\title{
Willful Ignorance
}

\author{
Jan Willem Wieland ${ }^{1}$
}

Accepted: 31 March 2016/Published online: 23 April 2016

(C) The Author(s) 2016. This article is published with open access at Springerlink.com

\begin{abstract}
Michelle Moody-Adams suggests that "the main obstacle to moral progress in social practices is the tendency to widespread affected ignorance of what can and should already be known." This explanation is promising, though to understand it we need to know what willful (affected, motivated, strategic) ignorance actually is. This paper presents a novel analysis of this concept, which builds upon Moody-Adams (1994) and is contrasted with a recent account by Lynch (2016).
\end{abstract}

Keywords Ignorance $\cdot$ Willful $\cdot$ Affected $\cdot$ Motivated $\cdot$ Strategic $\cdot$ Inconvenience

\section{Introduction}

According to the Global Slavery Index, there is more slavery today than ever before. This raises the question: why do so many people still work in slavery or slavery-like conditions? One straightforward explanation would be that we just cannot do any better. A more interesting explanation has been offered by Michelle Moody-Adams:

The main obstacle to moral progress in social practices is the tendency to widespread affected ignorance of what can and should already be known. (1999: 180)

The idea is not that we cannot do better, but that we do not want to know that we can, and indeed should, do better. Consider the slaveholder in ancient times. As one may imagine her, she was ignorant that keeping slaves is wrong. According to Moody-Adams, the slaveholder should and could have known better, and she's

Jan Willem Wieland

jjwwieland@gmail.com

1 Department of Philosophy, VU University Amsterdam, De Boelelaan 1105, 1081 HV Amsterdam, The Netherlands 
keeping slaves, and obstructing moral progress, only because her ignorance is affected or willful. ${ }^{1}$ This explanation is promising, but to understand it, we need to know what willful ignorance actually is. ${ }^{2}$ It seems to me that we do not have a clear grasp of this complex notion.

In a nutshell, willful ignorance can be seen as ignorance that is due to one's own will rather than to external barriers. You are ignorant not because it's excessively difficult to know better, but because you do not want to know better even though it's relatively easy to do so. In terms of necessary and sufficient conditions ${ }^{3}$ : S's ignorance of $\mathrm{p}$ is willful iff $S$ could figure out that $p$ is true if she would try to do so, but $S$ does not do it because she does not want to do it. On a general level, this simple account seems right. However, it is not very illuminating. Is this what obstructs moral progress? Surely you could have known about the weather conditions in Amsterdam at this very moment, and presumably you do not want to know this because you simply do not care. Nothing in that obstructs moral progress.

In contrast, interesting cases of willful ignorance are puzzling. They are cases where an agent, on the one hand, chooses to sustain her ignorance because this is somehow convenient for her, while, on the other hand, she may well be ignorant that she is doing this. The ancient slaveholder, for example, seems to sustain her ignorance in this way. But how can one choose to remain ignorant about certain inconvenient truths, yet remain ignorant in a relevant sense? In this paper, I'll discuss the details of this.

Here's the plan. In $\S 2$, I'll discuss Moody-Adams' suggestions on the issue. In $\S 3$, building on Moody-Adams' cases, I propose a specific account of willful ignorance. This account is largely intensional in the sense that it purports to define the meaning of 'willful ignorance', and to a lesser extent extensional and concerned with delineating the class of items that actually fall under the concept. In $\S 4$, I'll spell out two cases in some detail: the ancient slaveholder and the contemporary consumer. In $\S 5$, I'll raise a puzzle about willful ignorance and contrast my account with a recent proposal by Lynch (2016). Finally, in $\S 6$, I'll conclude and return to the question: in what sense does willful ignorance form an obstacle to moral progress?

One caveat. It's important to note that Moody-Adams' claim just mentioned is controversial. That is, not everyone accepts that willful ignorance is the main obstacle to moral progress. In the following, I will not provide direct support for this claim (or against it for that matter). Rather, the paper's main contribution is to provide a novel analysis of willful ignorance (which may be accepted by both Moody-Adams and her opponents).

\section{Moody-Adams}

In the following, I consider Moody-Adams' rich (1994) paper on this issue, and propose an account of willful ignorance on its basis. Moody-Adams argues against the following claims:

\footnotetext{
${ }^{1}$ I'll treat willful, affected, motivated, and strategic ignorance as the same (even though they might have different connotations), and use the term 'willful' throughout the paper. The concept has a long history, stretching back at least to Aquinas (Summa Theologiae, I-II, Q.6, art. 8).

${ }^{2}$ There are more reasons why studying this concept is important. For its role in legal contexts, cf. Husak and Callender (1994); Sarch (2014).

${ }^{3}$ In the paper, 'S' stands for an agent, 'p' for a proposition, and, later on, 'A' for an action or omission.
} 
(1) In certain cases, S's upbringing in a culture can render one unable to know that certain actions are wrong.

(2) In such cases, $\mathrm{S}$ is blameless for those actions.

(3) Whether (1) applies in a certain case is an empirical matter.

(4) For example, the ancient slaveholder was unable to know that slavery is wrong (and, per (2), she's blameless for keeping slaves).

As to (4), how can we determine whether the slaveholder could or could not have known that slavery is wrong? As Moody-Adams (1994: 294) rightly points out, one cannot simply consider evidence about what agents did and did not do at that time. After all, the fact that many people did not question slavery does not mean that they could not have done this. At any rate, Moody-Adams thinks the main problem has to do with (1). In her view, no culture can render one unable to know that certain actions are wrong. She writes:

every human being has the capacity to imagine (to conceive) that her social world might be organized on quite different principles ... one has the capacity to question existing social practices merely by virtue of learning to form the negation of any statement.

(1994: 296)

For example, the slaveholder could have imagined a world without slaves, and thus figured out that slavery is wrong. And what applies to slavery, applies to any wrongful practice: you'll be able to question it, and figure out that it's wrong. If this is so, (1) is false. No culture full of people who do not question slavery will take away your own capacity to question slavery. This also implies that it's not an empirical issue whether or not you are able to see that slavery is wrong (which refutes (3)). You possess this capacity, no matter the circumstances in which you might find yourself.

Let me add two qualifications. First, there is a distinction between moral and factual ignorance. The slaveholder might be factually ignorant that she keeps slaves. Suppose that, unbeknownst to her, she inherited a plantation abroad where workers are forced to work without pay. The slaveholder might also be morally ignorant that keeping slaves is wrong, even if she does know all the relevant facts (that she keeps slaves, that they suffer, that they are persons similar to herself, that they are unfree and lack any rights, etc.). This distinction matters. We cannot overcome all factual ignorance, that is, on the basis of our imagination. But perhaps we can overcome all moral ignorance in this way (at least in the cases I will be considering) as long as we know, or could know, all the relevant non-moral facts. The slaveholder could have figured out that her family's business is wrong so long as she knew, or could have known, that it involves slavery.

Second, in principle there's a distinction between the capacity to question slavery (or any practice) and the capacity to know that slavery is indeed wrong. After all, considering a question is not the same as finding the right answer. Relatedly, if proponents of (1) claim that one might have been unable to know that slavery is wrong, they do not seem to deny that one can form and understand the sentence 'slavery is wrong', but merely hold that one had no access to a good reason to think this. As Levy writes: "No doubt it is true that Greeks could form sentences like 'A world without slavery is possible.' But bare ability to imagine a possibility, in this sense, is very far from constituting a reason to take the proposal seriously." (2003: 
157) So to deny (1) in a relevant sense, we also have to assume that, no matter the culture you live in, you have access to a good reason to see that slavery is wrong. ${ }^{4}$

If we reject (1), (3) and (4), then (2) may fail as well. At least, $S$ is not to be excused on the basis of her culture. It might still be that $\mathrm{S}$ has other excuses. After all, being able to see that $\mathrm{A}$ is wrong should only be considered a necessary condition for blameworthiness for A, not a sufficient one. ${ }^{5}$ I'll have to leave (2) and the blameworthiness issue aside in this paper. ${ }^{6}$ What I will focus on is willful ignorance. If $\mathrm{S}$ were able to know that $\mathrm{A}$ is wrong (in the relevant sense), then her ignorance has to be explained in another way. She could have known, but did not want to. Here is what Moody-Adams says about willful ignorance:

Affected ignorance - choosing not to know what one can and should know - is a complex phenomenon, but sometimes it simply involves refusing to consider whether some practice in which one participates might be wrong. Sometimes - perhaps much of the time - cultures are perpetuated by human beings who are uncritically committed to the internal perspective on the way of life they hope to preserve. (1994: 296)

Listed as a set of conditions, the proposal seems to be this:

S's ignorance of $\mathrm{p}$ is willful if

(i) $\mathrm{p}$ implies that $\mathrm{A}$, an action of $\mathrm{S}$, is wrong;

(ii) $\mathrm{S}$ should have considered $\mathrm{p}$;

(iii) $\mathrm{S}$ could have considered $\mathrm{p}$;

(iv) but $\mathrm{S}$ does not consider $\mathrm{p}$;

(v) because $\mathrm{S}$ wants to keep on doing $\mathrm{A}$.

This list constitutes a sufficient condition. If all clauses are fulfilled, $\mathrm{S}$ is willfully ignorant. But I think it's not the case that all willful ignorance entails all these clauses. Moody-Adams herself is rather careful when it comes to (i), (iv) and (v), and I'd add that (ii) may not be necessary either. As noted in the introduction, you may stay willfully ignorant of the weather in Amsterdam, which does not entail (i) or (ii). For typically, weather conditions do not undermine the permissibility of your behaviour, nor are you supposed to know about them. Still, the proposal is supposed to capture a significant class of willful ignorance (including the case of the ancient slaveholder).

Clause (v) appears crucial: $\mathrm{S}$ does not consider $\mathrm{p}$, not for example because considering $\mathrm{p}$ is boring or excessively difficult, but because $S$ wants to keep on doing $A$. The ancient slaveholder does not consider the suffering and rights of her slaves because she wants to keep on exploiting them (more on this later). This 'self-interest clause' corresponds to MoodyAdams' claim that in many cases the willfully ignorant agent is, as she puts it in the citation just given, one who is "uncritically committed to the internal perspective on the way of life they hope to preserve"?

\footnotetext{
${ }^{4}$ That is, so long as it's not unreasonably difficult to know all the relevant non-moral facts, as per the first qualification. For further discussion, cf. Harman (2011); Wieland (2015).

${ }^{5}$ These are fairly standard assumptions: $\mathrm{S}$ is blameworthy for wrongful A done from ignorance only if $\mathrm{S}$ is blameworthy for her ignorance that A is wrong (among further necessary conditions, such as certain control or freedom conditions), and $\mathrm{S}$ is blameworthy for the latter only if S could have known that $\mathrm{A}$ is wrong (presumably among other necessary conditions).

${ }^{6}$ This issue has received some attention in the literature, cf. Calhoun (1989); Isaacs (1997); Benson (2001); Levy (2003); Scarre (2005); Pleasants (2008); Peacock (2011), among many others.

${ }^{7}$ Similar suggestions can also be found elsewhere (e.g. Calhoun 1989: 399).
} 


\section{My Account}

To test whether (i)-(v) are adequate conditions, let us consider the four examples we find in Moody-Adams (1994: 301). First, there is the torturer who uses specific language that masks her violent methods (such as calling one of them "the parrot's swing"), and remains willfully ignorant of the fact that "I am inflicting serious suffering." Second, there is the head of an investment bank who insists on not knowing how profit is made, and remains willfully ignorant of the fact that "illicit methods are being used to gain profit". Third, there is the mother who does not ask how her son can afford to give her expensive gifts, and remains willfully ignorant of the fact that "my son is a drug dealer." Finally, there is the university administrator who refuses to investigate a harassment allegation, and remains willfully ignorant of the fact that "a colleague is guilty of harassment." 8

These are four different kinds of cases. The torturer masks her wrongful behaviour. The banker refuses certain information about wrongful behaviour. The mother does not ask questions about wrongful behaviour. And the university administrator denies wrongful behaviour. Are these all cases of willful ignorance under (i)-(v)? Let us consider these clauses in turn.

Clause (i), or at least a close variant, is fulfilled in all of these cases. That one is inflicting serious suffering is wrong. That illicit methods are being used to gain profit is wrong. That one's son is dealing drugs is wrong. That there is harassment in one's school is wrong. In all these cases, there is some proposition which implies that a certain behaviour is wrong. But it is not always the agent's own behaviour. It might also be the behaviour of someone else (one's bank, one's son, or the people in one's school). To be sure, in these cases the agent seems still to be complicit in wrongdoing. It is not only wrong that one's son is dealing drugs, but also that one accepts his expensive gifts. It is not only wrong that there is harassment in one's school, but also that one fails to do something about it. Still, it would not be fully adequate to say that when $\mathrm{S}$ is willfully ignorant of $\mathrm{p}, \mathrm{p}$ merely indicates that $\mathrm{S}$ 's conduct is wrong (and not conduct of others), and this qualification has to be added to (i).

Before arguing that (v) calls for a more substantive revision, let me briefly show why (ii)-(iv) are fulfilled in all cases. As to (ii), in all cases the agent should know better. ${ }^{9}$ The torturer should know that her methods are violent, because knowing this will enable her to see that she should change her behaviour. The same applies in the other cases: the banker should know that the firm uses illicit methods, the mother should know that her son is a drug dealer, and the administrator should know about the harassment - this all because the given practices are wrong and knowing the relevant facts will enable them to see this (and to see, further, that they should change, or help change, those practices). As to (iii), in all cases the agent could know better. The torturer could see that she should not torture, the banker could find out how her bank makes profit, the mother could ask her son how it is possible that she gets so many gifts, and the administrator could investigate the harassment. In all of these cases, it's not unreasonably difficult to know better, and yet the agents in question do not do it, as per (iv).

\footnotetext{
${ }^{8}$ My discussion of the four cases may differ in some ways from how Moody-Adams presented them. For example, in Moody-Adams (1994: 301) the agents willfully avoid information about whether a certain proposition is true (irrespective of whether they are in fact true). For ease of discussion, I'll assume that the given propositions are true.

${ }_{9}^{9}$ Moody-Adams does not further unpack clause (ii). For the purposes of this paper, I'll assume that $\mathrm{S}$ should know $\mathrm{p}$ if knowing $\mathrm{p}$ enables her to see certain duties she has (such as stopping her slave keeping practices). The relationship between (ii) and (iii) is controversial, though given that (iii) is supposed to hold in most of the cases discussed in this paper, it does not really matter whether (ii) implies (iii), or whether they are independent clauses.
} 
At first sight, clause (v) appears promising. One is willfully ignorant whenever this in one's self-interest. Moreover, in the first two cases this seems to work. The torturer masks her behaviour because she wants to torture (she wants to do this, for example, in order to obtain certain information, or because she wants to follow orders ${ }^{10}$ ), and this is the most comfortable way to do it. Similarly, the banker refuses to hear about the practices in her firm because she wants to keep on making profit, and immoral ways might be the best ways to do it. ${ }^{11}$

However, this kind of motivation does not really seem to work in the other two cases. As we might imagine the mother, it's not the case that she does not ask questions about her son's behaviour because she wants to receive more gifts. Instead, she does not ask questions because she loves her son, and knowing he's dealing drugs is inconvenient. In this case, willful ignorance is not based on self-interest, but rather on what might be called 'other-interest'.

The fourth case, of the school administrator, is of yet a different kind. The administrator does not deny the harassment because she wants it to continue in her school. Nor does she deny it simply because she cares about the suspects or the victims. Rather, she denies it because she (or her school) failed to prevent them, which affects the image that she and others have of her (and her school). ${ }^{12}$ In this last case, willful ignorance is again based on selfinterest, but not on the forward-looking self-interest of the torturer and banker, but on what might be called backward-looking self-interest. The latter is called 'backward-looking', because the agent wants to stay ignorant about past behaviour (rather than facilitate future behaviour).

In principle, though, Moody-Adams's four cases can be unpacked in different ways. For example, in the mother case I think the other-interest reading is the most natural reading of the case. But this is not to say that the forward-looking self-interest or backward-looking selfinterest readings are impossible. Indeed, it might still be the case that the mother enjoys the expensive gifts (forward-looking self-interest), or that she feels responsible for the fact that her son became a drug dealer (backward-looking self-interest). Similarly, in the school administrator case, it might still be the case that the administrator does not care so much about her selfimage (backward-looking self-interest), but that she wants to be loyal to a colleague, and wants to believe the latter could not possibly be guilty (other-interest).

What do all these motivations for willful ignorance have in common? One might think that in all cases the ignorance is useful for the agent. But that's not exactly the right way to put it. The ignorance may seem useful for the torturer and banker, because it's easier for them to act immorally if they are ignorant. But it does not sound quite right to say that the ignorance is useful for the mother or the university administrator. In fact, in a clear sense it benefits none of the agents. For their ignorance prevents them from seeing that a certain behaviour is wrongful. Instead, what all these cases seem to have in common is that the agent wants to remain ignorant because it is convenient to do so, while knowledge of $\mathrm{p}$ is inconvenient. But

\footnotetext{
${ }^{10}$ Had her motives been sadistic, i.e. had she enjoyed the torturing, then she did not really have a reason to mask her conduct.

${ }^{11}$ Cf. also the initial analysis of the influential experiment by Dana et al. (2007), discussed in Spiekermann (2016). For the hypothesis that participants do not hide behind their ignorance in order to get off the hook for choosing unfairly, but really think it's permissible to act in certain ways without considering further information, cf. Spiekermann and Weiss (2015).

${ }^{12}$ For the relevance of self-image concerns in this context, cf. Dana et al. (2007); Bénabou and Tirole (2006); Grossman and Van der Weele (2016).
} 
the reason why this is inconvenient may differ, as I just showed on the basis of Moody-Adams' four cases.

Taking these modifications of clauses (i) and (v) into account, we get the following account of willful ignorance:

S's ignorance of $\mathrm{p}$ is willful if

(i*) $\mathrm{p}$ implies that $\mathrm{A}$, an action of $\mathrm{S}$ or another agent $\mathrm{S}^{*}$, is wrong;

(ii) $\mathrm{S}$ should have considered $\mathrm{p}$;

(iii) $\mathrm{S}$ could have considered $\mathrm{p}$;

(iv) but $\mathrm{S}$ does not consider $\mathrm{p}$;

$\left(\mathrm{v}^{*}\right)$ because this is inconvenient for $\mathrm{S}$, e.g.

- [forward-looking self-interest] $\mathrm{S}$ wants to keep on doing A in the future, since A has certain advantages for her over alternatives, or

- [backward-looking self-interest] S did not prevent $S^{*}$ or herself from doing A in the past, and this affects the image that $\mathrm{S}$ and/or others have of $\mathrm{S}$, or

- [other-interest] $\mathrm{S}$ cares about $\mathrm{S}^{*}$, and $\mathrm{S}$ does not want to know that $\mathrm{S}^{*}$ commits wrongful actions.

Perhaps the list of motivations under $\left(\mathrm{v}^{*}\right)$ is not exhaustive, but many cases fall under one (or several) of these three cases. In the remainder of this paper, I'll apply my account to two further cases, and discuss whether we need additional clauses (i.e. certain symptoms, a cultural dimension, and a certain awareness). My conclusion will be that we do not need further clauses, and that the account is adequate as it stands.

\section{Applications}

To illustrate my account in further detail, let us consider two cases: the notorious case of the ancient slaveholder, and the case of contemporary consumers. In the following I'll treat these cases as willful ignorance cases, and assume that $\left(i^{*}\right)-\left(\mathrm{v}^{*}\right)$ are fulfilled (even though it remains controversial whether (iii) is fulfilled, i.e. the clause according to which $\mathrm{S}$ could have considered $\mathrm{p}$ in a relevant sense and have known better).

As to (i*), let us say the ancient slaveholder was ignorant of the proposition "slaves suffer and have the right to their own lives" (or of any other proposition that implies that slaveholding is wrong). As to (ii), the slaveholder should have considered this proposition, because slaveholding is wrong, and considering it would have enabled her to see that her slaves suffer (which would have helped her realize that she should change her practices). As to (iii), she could have considered it: information that slaves suffer and have a right to their own lives was right in front of her (though one might think that this information was obscured by the culture in which she lived, and I'll address this soon). As to (iv) and $\left(\mathrm{v}^{*}\right)$, she did not consider whether slaveholding is wrong because not knowing that slaveholding is wrong was convenient for her. She might be motivated to remain ignorant for two different reasons. First, she exploited people, and the information that she did so affects the image she (and others) have of her (backward-looking self-interest). Second, she wants to keep her workers, and exploiting them ignorantly is less inconvenient (forward-looking self-interest). 
Very similar things apply contemporary consumers. ${ }^{13}$ As to (i*), many consumers are ignorant of the proposition "this product I want to buy (T-shirt, smartphone, coffee, etc.) is made in slavery-like working conditions". As to (ii), they should have considered this proposition, because buying such products is wrong (let us assume), and considering it would have enabled them to see that they would do better to buy an alternative product made in better working conditions. As to (iii), they could have known better by checking the labels, by searching for online information, and sometimes by asking questions at relevant places. As to (iv) and ( $\left.\mathrm{v}^{*}\right)$, they do not do this, because not knowing about working conditions is more convenient for them. Again, they might be motivated to remain ignorant for two different reasons. First, they may have bought many such products in the past and knowing that, in this, they contributed to the exploitation of people affects the image they have of themselves (backward-looking self-interest). Second, they may want to keep on buying cheap products, and doing this in ignorance is more convenient (forward-looking selfinterest).

In both cases, my account works well to explain willful ignorance in these cases. But more can be said, namely about certain symptoms that conjoin willful ignorance and about the cultural or social dimension of these cases. ${ }^{14}$

It can be hard to detect willful ignorance. After all, people's motivations are not always transparent (and hence it's not always clear whether and in what way clause ( $\left.\mathrm{v}^{*}\right)$ is fulfilled). Still, willful ignorance often manifests in certain symptoms, so we may detect the former on the basis of the latter. Moody-Adams suggests two such symptoms, namely "the readiness of some people to ask no questions about some state of affairs, in spite of evidence that an inquiry may be needed in order to stop or prevent wrongdoing" and "the tendency to avoid acknowledging our human fallibility" and "to avoid or deny this possibility", namely that "even our most deeply held convictions may be wrong" (1994: 301). ${ }^{15}$

The list of symptoms is likely to be larger. There is not only indifference, not asking questions about A's permissibility despite the availability of answers, and arrogance, thinking that one's take on A's permissibility is infallible in the face of its fallibility. There is also denial, telling oneself that doing A is permissible in the face of A being wrong; trivialization, telling oneself that A is morally unimportant in the face of A being morally important; and rationalization, making up non-sense reasons for $\mathrm{A}$ in the face of good reasons being available against A. ${ }^{16}$ For example, slaveholders may well tell themselves that slaveholding is permissible, or that the issue is unimportant, or that it is needed in order to realize other values such as democracy (cf. Peacock 2011: 74-5). Similarly, consumers may well tell themselves that

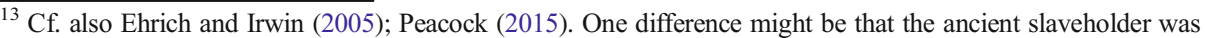
morally ignorant, while consumers are only factually ignorant (see $\S 2$ for this distinction).

${ }^{14}$ Also, something can be said about the doxastic attitude towards $\mathrm{p}$ (and towards the fact that they are avoiding information about p) that agents have when they are willfully ignorant of p. I'll address this in $\S 5$. For the moment, let us just assume that slaveholders and consumers are unaware that they are avoiding information.

15 These symptoms might, though need not, go together with general vices or insensitivities. If one manifests symptoms of willful ignorance, one fails to ask questions about a specific piece of behaviour A. If one manifests general vices one fails to ask questions about many issues.

16 These are symptoms of self-deception, and so I disagree with Lynch (2016) that willful ignorance and selfdeception are quite different things. In my view, both willful ignorance and self-deception can be non-intentional, the difference being that willful ignorance need not go together with symptoms of self-deception in all cases (as I'll explain below). The literature on self-deception is vast (for an overview of the controversy between intentionalists and non-intentionalists, cf. Deweese-Boyd 2012). I'll discuss the account of Lynch in due course.
} 
buying questionable products is permissible because it creates work (no matter in what conditions). ${ }^{17}$

Even though these symptoms go very naturally with willful ignorance, they are not required for the latter. For S may be willfully ignorant without telling herself that $\mathrm{A}$ is permissible, or morally irrelevant, or that her belief that $\mathrm{A}$ is permissible is infallible, and without confabulating reasons for $\mathrm{A}$. All that is needed is that $\mathrm{S}$ not have a belief that $\mathrm{A}$ is wrong (I'll qualify this in $\S 5$ ). As to indifference, can $\mathrm{S}$ be willfully ignorant and still ask questions about the thing she's ignorant of? The answer is not clear. For one cannot ask questions and yet remain ignorant, given that the answer is available to $\mathrm{S}$ (as per clause (iii)). Still, given that the symptom of indifference is entailed by clause (iv) (i.e. that $\mathrm{S}$ does not consider the issue), it need not be added as a separate condition to the account.

Willful ignorance might be culturally and socially embedded in two ways. First, the given behaviour A, though morally wrong, is often legally permissible. S can get away with doing A, so to speak. In certain ancient contexts, slavery was legally permissible. Moreover, slaveholders had a whole battery of cultural traditions to sustain their outlook and keep it from critical scrutiny. Similarly, buying products made in slavery-like working conditions is legally permissible in most contemporary contexts (even though slavery itself is widely condemned). Second, individuals are often not alone in their willful ignorance. Many peers perform A-like actions, are similarly ignorant, and manifest the same symptoms. Many other people kept slaves, and did not ask questions about the status of slaves in their society. Similarly, many other consumers buy cheap products made in unacceptable conditions, and do not ask questions about the cheap prices.

Again, such social embedding seems typical, but it's not required for willful ignorance. For example, it is absent in many of Moody-Adams' cases. The banker is probably surrounded by other willfully ignorant bankers, though the torturer, mother, and university administrator might be willfully ignorant, even if no one else is.

A few final comments on difficulty and degrees. One may wonder whether S's social embedding can make it too difficult for her to see that A is wrong. As we saw, Moody-Adams believes this to be a mistake. ${ }^{18}$ In cases of willful ignorance, $\mathrm{S}$ could figure out whether $\mathrm{A}$ is wrong by consulting a certain source, and this is not unreasonably demanding for S, given that the source is accessible to her and given that she does not have more important things to do. Slaveholders can pay attention to their slaves, consumers can check relevant websites, and in many cases they do not have more important things on their mind (that is, more important than the exploitation of people).

Yet, difficulty comes in degrees. There's a difference between the omission to call someone to obtain information and the omission to pick up the phone when people are calling you with that same kind of information. In this respect, the slaveholder and the consumer may differ. In the case of the slaveholder, as we might imagine her, information is staring her in the face. It's very difficult not to see that her slaves suffer. Paying attention might suffice to show her that slavery is wrong and that she should change her practices. In the case of the consumer, by contrast, it's easier not to see that the people in the supply chain suffer. After all, one is not directly confronted with them, and one needs to exert more effort to inform oneself.

\footnotetext{
${ }^{17}$ For such rationalizations (also called 'neutralizations'), cf. Chatzidakis et al. (2007); Eckhardt et al. (2010); Paharia et al. (2013); Gruber and Schlegelmilch (2014).

18 This is controversial: Guerrero (2007: 72) concurs, while Pleasants (2011: 150-1) disagrees.
} 
Given this, it's plausible that willful ignorance comes in degrees as well. In fact, all of the clauses I have discussed might be fulfilled to a greater or lesser extent. As to (i*), p might strongly or only weakly support the proposition that A is wrong. As to (ii), A might be wrong to a greater or lesser extent, and so more or less might depend on the fact that $\mathrm{S}$ informs herself about $\mathrm{p}$. As to (iii), as we just saw, information might be more or less accessible. As to (iv), $\mathrm{S}$ might exert more or less effort to avoid relevant information. Moreover, there may well be a certain proportional relationship between (iii) and (iv): the less effort is needed to access the information, the more effort is needed to avoid it, and vice versa. As to $\left(\mathrm{v}^{*}\right)$, knowledge that A is wrong might be more or less inconvenient. ${ }^{19}$

\section{A Puzzle}

Suppose $\mathrm{S}$ satisfies all clauses $\left(\mathrm{i}^{*}\right)-\left(\mathrm{v}^{*}\right)$, but is unaware that she does. Is she still willfully ignorant? Consider clauses (iv) and ( $\left.\mathrm{V}^{*}\right)$ in particular. Together, they state that $\mathrm{S}$ does not consider $\mathrm{p}$ because this is inconvenient for S. Importantly, for $\mathrm{S}$ to satisfy these clauses, is it not enough that $\mathrm{S}$ does not consider $\mathrm{p}$ and that considering $\mathrm{p}$ is inconvenient for $\mathrm{S}$. For some sort of connection need to obtain between these clauses, namely there has to be a causal relationship between the fact that considering $\mathrm{p}$ is inconvenient for $\mathrm{S}$ and the fact of her omission to consider $\mathrm{p}^{20}$ The question in the following will be whether we need more than this. Particularly, does the agent need to be aware of this connection, i.e. of the fact she does not consider $\mathrm{p}$ because this is inconvenient for her? In my view, the answer here is negative. But in order to show this, I need to tackle the following puzzle:

Horn (A) On the one hand, if S is fully unaware that she is avoiding information, then it is unclear that $\mathrm{S}$ is willfully avoiding information. This raises a paradox: how can $\mathrm{S}$ unconsciously choose not to know some inconvenient truth? For if S does so, it seems she is not really choosing not to consider whether $\mathrm{A}$ is wrong.

Horn (B) On the other hand, if S is aware that she is avoiding information about A, then it's not clear that $\mathrm{S}$ is really ignorant. At least $\mathrm{S}$ seems to know that there's a serious risk that $\mathrm{A}$ is wrong. This raises a paradox: how can $\mathrm{S}$ consciously choose not to know some inconvenient truth? For if S does so, it seems she is not really ignorant, but rather suspects its truth. This puzzle has recently been taken up by Lynch (2016: 509), who favours a solution along the following lines (which is in large part inspired by Husak and Callender 1994). According to Lynch, willful ignorance about $\mathrm{p}$ entails a suspicion that $\mathrm{p}$ is true. This suspicion covers a subtle attitudinal space. First, this attitude is weaker than a belief that $p$ is true. For if you believe that $p$ is true, you are not ignorant that $p$ is true. Second, the attitude is incompatible with a belief that $\mathrm{p}$ is false. For if you believe that $\mathrm{p}$ is false, you do not have a suspicion that $\mathrm{p}$ is true. Third, the attitude is incompatible with the absence of such a suspicion. For if you do not even have a

\footnotetext{
${ }^{19}$ For experimental studies on some of these gradual phenomena, cf. Grossman (2014); Grossman and Van der Weele (2016).

${ }^{20}$ The causal relation has to be non-deviant, i.e. S's omitting to consider $\mathrm{p}$ is a normal or typical upshot of the fact that this is inconvenient for $\mathrm{S}$.
} 
suspicion, your ignorance cannot be willful or intended. You'd just be ignorant, and the fact that you are avoiding information would not be your choice. ${ }^{21}$

The four cases by Moody-Adams might indeed involve such a suspicion (cf. also Levy 2003: 154). The torturer may suspect that her methods are wrongfully violent (even though she may tell herself that they are justifiably violent). The banker may suspect that her firm uses illicit methods to gain profit. The mother may suspect that her son is a drug dealer. And the university administrator may suspect harassment. This may not mean that they have a clear attitude with a well-defined propositional content of the form 'I could and should inform myself about the given action A, but I am avoiding relevant information about $\mathrm{A}$ because this is convenient for me'. But it does mean that they have a vague suspicion that $\mathrm{p}$ might be true (and that A might be wrong). ${ }^{22}$

Suspicions come with a certain awareness. If you suspect that $p$ is true, you are aware that $p$ might be true (that there's a certain risk that $\mathrm{p}$ is true, so to speak). As just noted, the content of suspicions can be more or less well-defined. The mother might only be aware of the fact that something is wrong with the presents of her son. But she might also be aware of the fact that he's a drug dealer, and that she does not want to know more about it. And, as Lynch adds, suspicions can be stronger or weaker. The mother might strongly suspect her son is a drug dealer, or only weakly suspect this. What matters on his account is that the suspicion amounts neither to a belief in the given content nor to a disbelief in it.

In my view, though, we need not add a suspicion or awareness requirement on willful ignorance. The latter is compatible with suspicions, but there's also willful ignorance without them. Hence, my view is more liberal than Lynch's: it considers the class of willful ignorance to be larger. In my view, what matters for willful ignorance is not so much a specific attitude of the agent, but the fact that she is avoiding inconvenient information, though not due to external barriers (as I put it in $§ 1$ ). But if this is so, both horns of the puzzle are mistaken. Let me consider each in turn.

Horn (A) suggests that willful ignorance seems incompatible with full unawareness. Contra (A), I need to show that if S lacks any suspicion and awareness, then it might still be that she is willfully ignorant in a relevant sense.

First, consider the two applications from $\S 4$. I can imagine that there were many slaveholders who had no suspicion that their slaves were suffering. Clearly, there are many consumers today who have no suspicion that the products they buy are made in slavery-like conditions. Yet they can be willfully ignorant. After all, they are avoiding inconvenient information, and their ignorance is not due to external barriers.

In fact, assuming that only people with suspicions are willfully ignorant has counterintuitive consequences. Arguably, consumers who care about working conditions are often suspicious of the products they buy, while consumers who do not care typically lack such suspicions. Would this mean that only the concerned consumers are willfully ignorant? That's counterintuitive. After all, the external barriers to obtaining more information about working conditions are exactly the same for both kinds of consumers.

The same applies to interesting versions of Moody-Adams' cases. Suppose the mother or the school administrator lacks any suspicion. The mother might even disbelieve that her son

\footnotetext{
${ }^{21}$ In addition, as Lynch suggests (following Husak and Callender 1994: 40), the attitude must be justified by the available evidence. You might be very suspicious because you are delusional, but that does not make you willfully ignorant. In all of Moody-Adams's cases, if the agents have suspicions, they seem well-supported by the available evidence.

${ }^{22}$ As Moody-Adams suggested to me.
} 
deals drugs, and the administrator might disbelieve that there is harassment in her school (and I will assume that these disbeliefs do not go together with suspicions to the contrary). Would that mean they are not willfully ignorant? Surely not. Their ignorance is still due to their own will rather than to external barriers, given all the available evidence to the contrary.

If this is right, one may be fully unaware that one is willfully ignorant. Lynch may be right that in such cases the ignorance is not intended, in a relevant sense. But, it seems to me that not all willful ignorance is essentially intentional or the upshot of a clear plan. What matters is that it's not the upshot of external barriers. If you satisfy (i*)-( $\left.\mathrm{v}^{*}\right)$, then your ignorance is, in the sense of these conditions, still up to you. Let me defend this from two objections.

First objection: if one has no awareness clause, then one might avoid information for the wrong reasons, that is, for reasons that have nothing to do with the inconvenience of the information.

Suppose someone calls you, but you do not know what it is about, and decide not to pick up the phone because you do not like phone calls (or perhaps you think it's all-things-considered better to do something else with your time). Suppose the person calling had inconvenient information about the permissibility of your behaviour, though you had no idea, and not picking up the phone had nothing to do with it. Hence, you are avoiding inconvenient information. You could have picked up the phone (which means that clause (iii) is satisfied), and on the assumption that you had an obligation to pick up (so that clause (ii) is satisfied as well), you seem to be willfully ignorant on my account.

In response, I do not think it's clear that this follows. First, clause (iii) is satisfied only temporarily, and hence you are not systematically avoiding information. To address this, we might suppose that they call you each and every day and that you never pick up. Again, we would not want to call this willful ignorance so long as you are motivated only by your aversion to phone calls. Still, my account would not consider this a case of willful ignorance unless there is a causal relationship between your repeated failure to pick up the phone and the fact that the information is inconvenient for you, and this is unclear in this case. ${ }^{23}$

Second objection: "Willful ignorance requires some awareness that the ignorance is convenient. For sometimes we are lucky to have ignorance that meets the other conditions $\left(i^{*}\right)-\left(\mathrm{V}^{*}\right)$. After ignorance is corrected we might look back and say, "Wow, good that I was ignorant. It was convenient for me." But, this shows that the ignorance wasn't willful." ${ }^{24}$ So if you were unaware that you were avoiding inconvenient truths, then afterwards you might be glad that this happened to you. And if you are glad in this way, you seem to acknowledge that you did not really choose to be ignorant.

The objection may seem sensible, but my account can respond to it. Namely, if you fulfil the inconvenience clause (vi*), then you cannot say "Wow, good that I was ignorant". After all, the ignorance was convenient, and the information one receives is inconvenient. The information might reveal that one can no longer do A (forward-looking self-interest), or it might affect your image (backward-looking self-interest), or it might reveal something about someone you care about (other-interest). Furthermore, if you cannot be happy that you were ignorant, you are not committed to acknowledge that you did not really choose to be ignorant, as the objection has it.

\footnotetext{
${ }^{23}$ I did not offer a further analysis of what this causal relation entails, though it is plausible to assume that this relation can obtain even when the agent is unaware of it.

${ }^{24}$ Quoting Phil Robichaud. We are lucky in such a case, I take it, because our ignorance worked out well for us, and not because it was exceptional that the conditions were fulfilled (as the first objection had it).
} 
Horn (B) suggests that willful ignorance seems incompatible with a certain awareness. Contra (B), I need to show that willful ignorance is not only compatible with a certain unawareness (as I just argued), but also with various kinds of awareness.

First Case $\mathrm{S}$ has a very weak reason to suspect that $\mathrm{A}$ is wrong, and decides in full awareness not to consider further information about A's wrongness. Suppose you know that $10 \%$ of this company's products are made in slavery-like conditions, but do not know whether this specific product is made in such conditions. Despite your weak suspicion that buying it may be wrong, you decide not to consider further information and just to buy it. ${ }^{25}$ This seems to be a clear case of willful ignorance.

Second Case $\mathrm{S}$ has a strong reason to suspect that $\mathrm{A}$ is wrong, and decides in full awareness not to consider further information about A's wrongness. Suppose you know that $90 \%$ of this company's products are made in slavery-like conditions, but do not know whether this specific product is made in such conditions. Despite your strong suspicion that buying it may be wrong, you decide not to consider further information and just to buy it. This also seems to be a case of willful ignorance (and the same would apply to any further variant of these cases ${ }^{26}$ ).

Final Case S not only has a strong suspicion that A is wrong, she also believes it. Suppose you rightly believe that all products are made in slavery-like conditions. Still, this information is inconvenient for you, and you suppress your belief by masking your consuming behaviour (just as the torturer masks her violent methods) and by avoiding information which would bring your belief to the center of your awareness. You are not fully aware that your purchase is wrong, but you do believe that it is deep down. In such a case, I think you might still be called willfully ignorant.

All in all, given that on my account willful ignorance is about avoiding inconvenient information, it does not really matter what attitude the agent has, and willful ignorance is compatible with awareness and unawareness of various kinds. In my view, the only attitude incompatible with willful ignorance is full awareness that one is doing something wrong. For if one is fully aware of this, one is simply not ignorant. ${ }^{27}$

\section{Conclusion}

I have offered my analysis of willful ignorance in $\S 3$, and in the subsequent sections I have argued why it need not be supplemented with further conditions. To see the innovative aspects of my account, it's helpful to compare it to the account by Lynch (2016), mentioned earlier. On Lynch's view, as we have seen, willful ignorance essentially entails a certain attitude, namely a suspicion that the proposition $\mathrm{S}$ is ignorant about is true. I have argued that such suspicions needn't be present in all cases.

On both accounts, it's important that $\mathrm{S}$ does not inform herself because she does not want to. To clarify, Lynch cites the suggestion by Husak \& Callender that: "the willfully ignorant

\footnotetext{
${ }^{25}$ Surely, sometimes such risk-taking might be justified, namely if S had to act and doing A is all-thingsconsidered better than waiting for more information.

${ }^{26}$ Including the experiment by Dana et al. (2007), where participants know that $50 \%$ of the outcomes are unfair.

${ }^{27}$ We do not need to add this to our list of conditions $\left(\mathrm{i}^{*}\right)-\left(\mathrm{v}^{*}\right)$. For if $\mathrm{S}$ is fully aware that A is wrong, I'd think S has no obligation to consider the issue further (and clause (ii) would fail).
} 
defendant must have a given motive for remaining unaware of the truth ... His failure to gain more information cannot be due to mere laziness, stupidity, or the absence of curiosity." (1994: 40) Of course, the question is what this motivation might amount to. I have explained this in terms of my inconvenience clause: $\mathrm{S}$ does not consider certain information because this information is inconvenient for her (in one of the three senses that I have distinguished).

One further difference is that I consider my account only sufficient, not necessary. As suggested in $\S 1$, in principle any case of ignorance where $\mathrm{S}$ could know better, but does not want to know better (such as ignorance about the weather conditions in Amsterdam) seems to count as willful ignorance. Indeed, one may be willfully ignorant of inconvenient information as well as other kinds of information (such as irrelevant information). ${ }^{28}$ At any rate, given that the latter are less interesting, it's no problem that my account does not capture such further cases. $^{29}$

This brings me to the issue I started with: moral progress. Why is there still so much slavery in the world? Why do so many consumers today buy products made in unacceptable working conditions? As said, Moody-Adams suggests that willful ignorance is the main obstacle to moral progress. Recently, Pleasants (2011) has criticized this claim by arguing that it is implausible that people could have remained willfully ignorant about slavery for so long. According to Pleasants, it's more plausible to think that they could not have known better since no plausible alternative to such a useful institutionalized practice was available to them. The disagreement between Moody-Adams and Pleasants involves an intricate issue about the relation between individuals and cultures, which is something I cannot delve into here. Let me just make two points concerning why one may want to resist Pleasants' criticism.

First, I acknowledge that a lack of plausible alternatives to useful institutionalized practices might hinder moral progress as well. Still, it is unclear that slaveholders were forced to keep slaves, or that most consumers are forced to buy cheap products made in unacceptable conditions. In these cases (as well as in the four further cases by Moody-Adams I have discussed), plausible alternatives seem to me the default situation. If this is right, moreover, the explanation of why there's so little moral progress has to be sought elsewhere.

Second, the claim that it is implausible that people could have stayed willfully ignorant for so long underestimates the force of willful ignorance. What obstructs moral progress, it seems to me, is willful ignorance motivated by what I have called 'backward-looking' and 'forward-looking selfinterest'. We do not want to consider whether our practices are wrong, first because we have engaged in them for too long, and realizing this will seriously affect the image we have of ourselves. Second, we do not want to consider it, because it's in our interests if we stay ignorant: slaveholders want to keep their cheap workers, and consumers wants to keep on buying cheap clothes.

While I do not take these brief comments to be at all decisive, I do hope they will provoke further debate. The next and important question is whether we are responsible and indeed blameworthy for our willful ignorance. Is it the case that if our ignorance is willful, it is blameworthy and does not excuse us from wrongdoing? This is a complex question, to be addressed some other time. At least now we have a novel proposal on the table concerning what willful ignorance amounts to.

\footnotetext{
${ }^{28}$ According to Lynch (2016: 511-2), ignorance about the weather conditions does not count as willful, because 'willful' has a pejorative tone which is missing here.

${ }^{29}$ Our accounts coincide on other points. One comment on Lynch's requirement that $\mathrm{p}$ has to be true (for without truth, there's nothing to be ignorant about). Typically, this clause is entailed by the clause that $\mathrm{S}$ should consider $\mathrm{p}$ (if $\mathrm{p}$ is false, $\mathrm{S}$ does not have an obligation to consider $\mathrm{p}$ ), and the latter is included in my account. Still, one may wonder whether the clause is really needed given that one may willfully avoid inconvenient information about a false proposition.
} 
Acknowledgments Thanks to: Kevin Lynch, Michelle Moody-Adams, Phil Robichaud, Joël van der Weele, and the two reviewers for comments.

\section{Compliance with Ethical Standards}

Funding Agency This paper has been written in the context of the research project 'We should know better. An inquiry at the crossroads of ethics and epistemology' supported by the Netherlands Organization for Scientific Research (NWO).

Open Access This article is distributed under the terms of the Creative Commons Attribution 4.0 International License (http://creativecommons.org/licenses/by/4.0/), which permits unrestricted use, distribution, and reproduction in any medium, provided you give appropriate credit to the original author(s) and the source, provide a link to the Creative Commons license, and indicate if changes were made.

\section{References}

Bénabou R, Tirole J (2006) Incentives and prosocial behavior. Am Econ Rev 96:1652-1678

Benson P (2001) Culture and responsibility. J Soc Philos 32:610-620

Calhoun C (1989) Responsibility and reproach. Ethics 99:389-406

Chatzidakis A, Hibbert S, Smith AP (2007) Why people don't take their concerns about fair trade to the supermarket: the role of neutralisation. J Bus Ethics 74:89-100

Dana J, Weber RA, Kuang JX (2007) Exploiting moral wiggle room: experiments demonstrating an illusory preference for fairness. Economic Theory 33:67-80

Deweese-Boyd, J (2012) Self-deception. Stanford encyclopedia of philosophy

Eckhardt GM, Belk R, Devinney TM (2010) Why don't consumers consume ethically? J Consum Behav 9:426-436

Ehrich KR, Irwin JR (2005) Willful ignorance in the request for product attribute information. J Mark Res 42:266-277

Grossman Z (2014) Strategic ignorance and the robustness of social preferences. Manag Sci 60:2659-2665

Grossman Z, Van der Weele JJ (2016) Self-image and willful ignorance in social decisions. J Eur Econ Assoc

Gruber V, Schlegelmilch BB (2014) How techniques of neutralization legitimize norm- and attitude-inconsistent consumer behavior. J Bus Ethics 121:29-45

Guerrero AA (2007) Don't know, don't kill: moral ignorance, culpability, and caution. Philos Stud 136:59-97

Harman E (2011) Does moral ignorance exculpate? Ratio 24:443-468

Husak DN, Callender CA (1994) Wilful ignorance, knowledge, and the 'equal culpability' thesis. Wisconsin Law Review 1:29-69

Isaacs T (1997) Cultural context and moral responsibility. Ethics 107:670-684

Levy N (2003) Cultural membership and moral responsibility. Monist 86:145-163

Lynch K (2016) Willful ignorance and self-deception. Philos Stud 173:505-523

Moody-Adams MM (1994) Culture, responsibility, and affected ignorance. Ethics 104:291-309

Moody-Adams MM (1999) The idea of moral progress. Metaphilosophy 30:168-185

Paharia N, Vohs KD, Deshpandé R (2013) Sweatshop labor is wrong unless the shoes are cute: cognition can both help and hurt moral motivated reasoning. Organ Behav Hum Decis Processes 121:81-88

Peacock M (2011) Inability, culpability and affected ignorance. Hist Hum Sci 24:65-81

Peacock M (2015) Market processes and the ethics of consumption. SAGE Open. doi:10.1177/ 2158244015585998

Pleasants N (2008) Institutional wrongdoing and moral perception. J Soc Philos 39:96-115

Pleasants N (2011) Moral argument is not enough: the persistence of slavery and the emergence of abolition. Philos Top 38:139-160

Sarch AF (2014) Willful ignorance, culpability and the criminal law. St John's Law Review 88:1023-1101

Scarre G (2005) Excusing the inexcusable? Moral responsibility and ideologically-motivated wrongdoing. J Soc Philos 36:457-472

Spiekermann K (2016) Four types of moral wriggle room: uncovering mechanisms of racial discrimination. In M Fricker \& M Brady (eds.), The epistemic life of groups. OUP

Spiekermann K, Weiss A (2015) Objective and subjective compliance: how moral wiggle room opens. Games \& Economic Behaviour

Wieland, JW (2015) What's special about moral ignorance? Ratio. doi:10.1111/rati.12127 